\section{JAOA education issue highlights profession's growth}

Since the founding of the American School of Osteopathy in 1892, osteopathic medicine and osteopathic medical education have made giant strides.

During the past two decades alone, the osteopathic medical profession has experienced dramatic growth. According to a recent government report, osteopathic medicine presently is the most rapidly growing healthcare profession in the nation. The report, prepared by the US Public Health Service's Health Resources and Services Administration, predicts that this momentum will continue into the next century. By the year 2000, the report estimates that the number of osteopathic physicians will increase by nearly $80 \%$; by 2020 , that number will grow by $177 \%$.

This impressive growth is reflected in the data and information that are presented in this annual education issue of the JAOA: more students are applying to osteopathic medical school, the academic requirements are tougher, and new options are appearing for postgraduate osteopathic medical education.

The format of this year's education edition is intended to provide a rich source of data that profile the osteopathic medical profession and its educational resources today. AOA staff have prepared the five articles that are published here by drawing on information compiled by the American Osteopathic Association and the American Association of Colleges of Osteopathic Medicine.

These articles cover the full spectrum of osteopathic medical education:

- "Undergraduate Osteopathic Medical Education" focuses on osteopathic medical school applicants and students--who they are, where they are from, and how they perform academically. Details and information are included on osteopathic medical school curricula, faculty, and the accreditation process.
- "Osteopathic Postdoctoral Education in Transition" discusses important changes that are occurring in graduate osteopathic medical education, including recent options proposed and accepted in principle by the AOA Board of Trustees and House of Delegates. Current statistics are presented on internships, residencies, and certification.

- "US Osteopathic Medical School Finances" describes revenue sources for osteopathic medical schools, the deployment of these monies, and changing revenue patterns. Sources for student loans and scholarships also are identified.

- "AOA Continuing Osteopathic Medical Education" describes current AOA policies on continuing osteopathic medical education program organization and structure, discusses trends in CME, and outlines recent important changes in AOA CME policies.

- "History of Osteopathic Medical Education Accreditation" presents a brief history of the development of AOA as the official accrediting body for osteopathic medical education and outlines current accreditation structures.

These articles summarize the status of osteopathic medical education today and provide a means to measure future growth of the profession. Because osteopathic medicine is the nation's fastest growing healthcare profession, ongoing changes can be expected as we approach the 21 st century.

SANDRA M. WILLIAMSON

Executive Editor 
